\title{
Special Editions: Membranes in Water and Sustainable Water Processing
}

\section{Editorial}

Throughout the world, the importance of water has been emphasized repeatedly by all parties that are concerned with the sustainability of this precious resource. The United Nations (UN) has estimated that 1.2 billion people are currently living in areas considered to suffer from a physical scarcity of clean water, while a total of 1.6 billion people (one quarter of the world's population) are facing economic water shortages. At the same time, unprecedented demands on fresh water supplies are being exerted globally. Among the factors that are contributing to these pressures are a booming population, an increase in demand for water resources, climate change, the contamination of available water resources, and the mismanagement of water resources and their overuse or wastage. Clean water shortages will eventually limit economic growth and food supplies, while a lack of water sanitation is already associated with tragic levels of infant mortality in the developing world. In the absence of decisive action, driven by sustainable technology and its implementation, the situation will only get worse. Because of this, research and development on the many facets of water as a precious resource is rapidly increasing throughout the world.

The Journal of Water Process Engineering (JWPE) was launched in 2014 with the intention of promoting R\&D into water resources through the publication of refereed, high-quality research papers with significant novelty and impact in all areas of the process engineering of water and wastewater. As such, we are pleased to announce the publication of two special issues focusing on Membranes in Water and Sustainable Water Processing

Over the last two decades, R\&D in membrane technology and especially for water and wastewater treatment has seen an exponential growth. Among the many advantages that membrane technology can offer are smaller plant footprints, reduced sludge production, a higher quality of treated water, and a minimum requirement for chemicals. Notwithstanding these advantages, membrane technology still requires further $R \& D$ on issues related to membrane fouling, increased selectivity, improvement in membrane lifetime and chemical resistance, and lower energy consumption. With this in mind, the Journal of Water Process Engineering has initiated a Special Issue focusing on Membranes in Water. A total of eighteen papers were accepted for publication in this Special Issue. Among the topics that are presented include synthesis of novel membranes for various applications in water treatment, modification of membranes through incorporation of additives such as nanoparticles, improved operation of membrane processes through innovative processing conditions, and newer membrane processes for water and wastewater treatment such as forward osmosis and pressure retarded osmosis.

The Journal of Water Process Engineering was also proud to host the First International Conference on Sustainable Water Processing during September $11^{\text {th }}-14^{\text {th }} 2016$, in the coastal town of Sitges, Spain. This was perhaps the first international conference ever to address these pressing challenges in a direct, integrated and holistic way. As well as the potential technological solutions, the environmental, economic, societal and sustainability challenges were also addressed. All delegates who made presentations at the conference were invited to submit a paper of their work, which was subject to the normal peer review process for the journal. The result is the following special edition on Sustainable Water Processing. 
We hope you will find the papers in these two special issues interesting, and that they will offer you inspiration and help as you search for sustainable solutions to water processing in an ever more water-scarce world.

\section{Editorial}

The Conference Chairs, and Journal Co-Editors for both special issues:

Professor Nick Hankins, The University of Oxford, U.K.

Professor Abdul Wahab Mohammad, Universiti Kebangsaan Malaysia

Guest Editor for Membranes in Water:

Prof Vitaly Gitis, Ben Gurion University, Israel

Guest Editor for Sustainable Water Processing:

Prof Sher Jamal Khan, NUST, Pakistan 